\title{
Incidence of IDDM during 1988-1992 in Zagreb, Croatia
}

\author{
G. Roglić ${ }^{1}$, I.Pavlić-Renar ${ }^{1}$, S. Šestan-Crnek ${ }^{1}$, M. Prašek ${ }^{1}$, M. Kadrnka-Lovrenčic ${ }^{2}$, A. Radica ${ }^{3}$,̌. Metelko ${ }^{1}$ \\ ${ }^{1}$ The Vuk Vrhovac Institute for Diabetes, Endocrinology and Metabolic Diseases, Zagreb, Croatia \\ ${ }^{2}$ Department of Pediatrics, Clinical Hospital "Sestre Milosrdnice", Zagreb, Croatia \\ ${ }^{3}$ Department of Pediatrics, Clinical Hospital "Rebro", Zagreb, Croatia
}

Summary The objective of this study was to determine the incidence of insulin-dependent diabetes mellitus (IDDM) in the population of Zagreb, Croatia, during 1988-1992. A centralized diabetes registry was the primary source of data, while secondary sources were used to assess ascertainment. A total of 282 new cases of IDDM were diagnosed in the study period, the primary and secondary sources identifying annually $93-100 \%$ of the cases. The annual incidence rate ranged from 5.6 per 100,000 to 6.6 per 100,000 . Early fatality in persons older than 50 years was the major cause of underascertainment. The inci- dence peaked in the 10-14 years age group (12.4 per $100,000)$, and remained stable after age 24 years. Males had a significantly higher incidence in the 5-9 and 24-44 years age groups. In the $45-54$ years age group, females had a significantly higher incidence. No seasonality was observed. Despite the war conditions in Croatia, the low overall IDDM incidence rates did not change significantly during the study period. [Diabetologia (1995) 38: 550-554]

Key words Insulin-dependent diabetes, incidence, epidemiology, war.
Since the early 1980 s an increasing body of knowledge has been accumulated in a standardised manner on the incidence of insulin-dependent diabetes mellitus (IDDM) throughout the world $[1,2]$. However, these standardised incidence registries mostly provide data for the $0-14$ years age group. Only a few studies have provided data on the incidence of IDDM in persons older than 30 years, with somewhat different definitions of IDDM [3-8]. To our knowledge, there are no reports of population-based studies of IDDM incidence in persons older than 30 years in a population of Slavic origin. In Croatia registration of diabetic patients has been compulsory since 1975 [9]. Previous research has indicated that the incidence of childhood diabetes in the population of Zagreb, Croatia was low during 1970-1989

Received: 27 May 1994 and in revised form: 25 July 1994

Corresponding author: Dr. G. Roglić, Vuk Vrhovac Institute, Dugi Dol 4a, 41000 Zagreb, Croatia

Abbreviations: IDDM, Insulin-dependent diabetes mellitus; DKA, diabetic ketoacidosis.
[10]. This study was undertaken to determine the incidence of IDDM in the total population of Zagreb during 1988-1992, and to test the hypothesis that the war in Croatia affected the incidence of IDDM in the residents of Zagreb. Stress has been suspected to play a role in the onset of IDDM. The literature on psychoimmunology suggests several mechanisms by which psychological stress may be implicated in the development of IDDM [11], but conclusive evidence is lacking.

\section{Subjects and methods}

Zagreb, the capital of Croatia and its largest city, covers an area of 1,705 square $\mathrm{km}$, the population size being 933,914 in 1991 , which is about $20 \%$ of the total Croatian population. Base population estimates were obtained from the Central Bureau of Statistics of Croatia [12], based on decennial 1981 and 1991 population censuses, and intercensual estimates for 1988, 1989, 1990, and 1992. All persons suspected of having diabetes in Croatia are referred to a diabetologist for diagnosis and initial treatment. In Zagreb, all suspected cases are referted to one of the two pediatric diabetes centres if the per- 
Table 1. Number of cases of IDDM and completeness of case ascertainment for primary source and secondary sources in $\mathrm{Za}$ greb 1988-1992

\begin{tabular}{lccccc}
\hline Year & $\begin{array}{l}\text { Pri- } \\
\text { mary }\end{array}$ & $\begin{array}{l}\text { Secon- } \\
\text { dary }\end{array}$ & Both & $\begin{array}{l}\text { Total observ- } \\
\text { ed }(\% \text { of to- } \\
\text { tal estimated })\end{array}$ & $\begin{array}{l}\text { Total } \\
\text { estimated } \\
(95 \% \mathrm{Cl})\end{array}$ \\
\hline 1988 & 59 & 31 & 29 & $61(96.8)$ & $63(59-67)$ \\
1989 & 53 & 20 & 20 & $53(100)$ & 53 \\
1990 & 56 & 27 & 26 & $57(98.3)$ & $58(55-61)$ \\
1991 & 52 & 21 & 19 & $54(94.7)$ & $57(51-63)$ \\
1992 & 54 & 26 & 23 & $57(93.4)$ & $61(55-67)$ \\
$88-92$ & 274 & 125 & 117 & $282(96.2)$ & $293(283-303)$ \\
\hline
\end{tabular}

son is less than 15 years old, or to the Institute for Diabetes. All persons hospitalized for any reason are referred to a diabetologist for follow-up if diabetes is diagnosed during hospital treatment. Upon diagnosis all persons are registered in the central diabetes registry. Insulin syringes, self-monitoring devices and test-strips can only be obtained free of charge if prescribed by a diabetologist. There are no private hospitals or private diabetologists. The diabetes registry was the primary source of IDDM incidence data. In order to include a person in the calculation of IDDM incidence rates, he or she had to: 1) have diabetes diagnosed after 31 December 1987 and before 1 January $1993 ; 2$ ) reside in the administrative area of $\mathrm{Za}$ greb at the time of diagnosis; 3 ) present with laboratory evidence of ketonuria or ketoacidosis at the time of diagnosis and/or be placed on insulin treatment within 1 week of diagnosis; 4) remain on continuous insulin treatment, allowing for a brief "honeymoon" period in the first year of treatment. All case records of persons registered in the study period were examined.

To ensure as complete a case ascertainment as possible and to estimate the actual number of cases, two additional independent data sources were used together with the central diabetes registry. One of them consisted of the death certificates of all deceased in the Zagreb area during 1988-1991. These death certificates were checked to identify persons that had been diagnosed as having diabetes and who died before being registered. All certificates with the diagnosis of diabetes mellitus were cross-referenced with the registry data. The medical records of deceased persons not found in the registry were reviewed to determine the type of diabetes.

The Association of Diabetic Patients is an independent charity organization which organizes free educational holidays for diabetic children, distributes free food packages and provides other kinds of material aid to its members. The mem- bership files were reviewed for persons on insulin treatment, diagnosed 1988-1992, and the identified persons' data were checked for registration in the central diabetes registry. Refugees and displaced persons living in Zagreb at the time of diagnosis were not included in the numerators for incidence calculation because of the uncertain number of all refugees and displaced persons in Zagreb.

\section{Statistical analysis}

Completeness of ascertainment was estimated by the twosource capture-recapture method, merging all data from secondary sources [13]. The observed numbers of cases in each age group and calendar year were used in the calculation of incidence rates [14].

The incidence rates are expressed as age-and sex-specific rates per 100,000 population, and rates for the total population are expressed as age-adjusted rates per 100,000 population, using the direct method and the total population of Croatia as the standard population $[12,15]$. Denominators of incidence rates over 1988-1992 are the sum of the denominators of each year. Assuming a Poisson distribution of the observed number of cases, the $95 \%$ confidence intervals (Cls) were computed [16]. Statistical analysis of temporal trend was performed by linear regression, using SAS statistical software. A non-parametric procedure was used for testing for seasonal variation in diagnosis [17]. Seasons were defined in 3-month windows beginning with January.

\section{Results}

In the period 1988-1992, 282 incident cases of IDDM were identified from among the residents of Zagreb. Persons with secondary diabetes were not included. The central diabetes registry identified 274 cases. The data for estimation of completeness are presented in Table 1. All persons identified through the Association of Diabetic Patients had previously been identified through the primary source. Death certificates identified eight persons who escaped registration because of death on diagnosis: two males (aged 62 and 63 years in 1988, one female aged 66 years in 1990 , a male aged 61 and a female aged 69 years in 1991, two females (aged 54 and 26 years) and one

Table 2. Age- and sex-specific incidence rates of IDDM (per 100,000 person-years) in Zagreb, 1988-1992

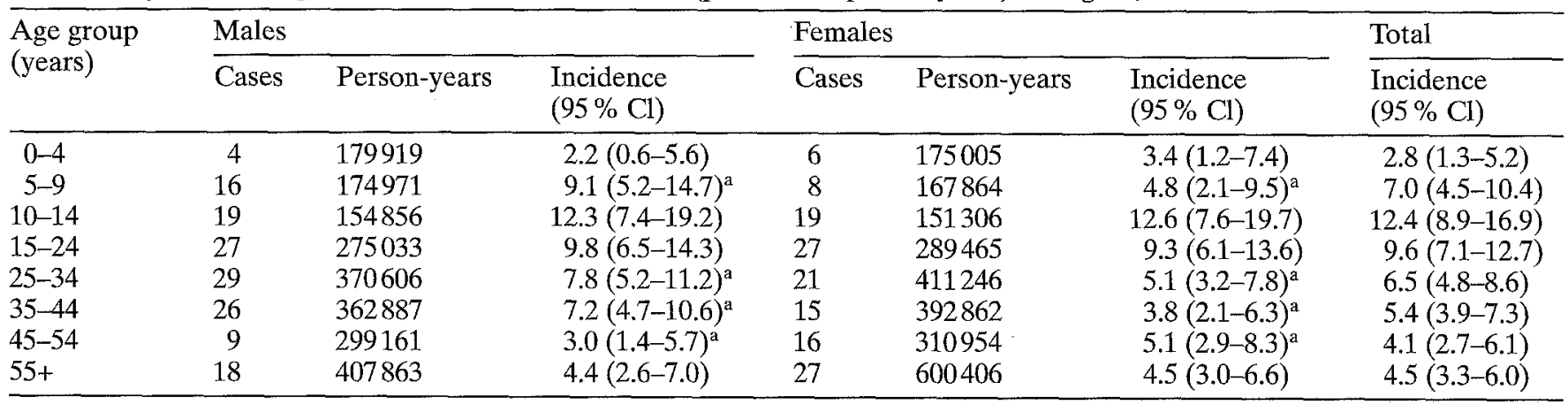

${ }^{a}$ Significant difference, $p<0.05$ 
Table 3. Annual incidence of IDDM (per 100,000) in Zagreb

\begin{tabular}{llllll}
\hline & 1988 & 1989 & 1990 & 1991 & 1992 \\
\hline Males & & & & & \\
$n$ & 32 & 28 & 27 & 28 & 31 \\
Incidence & 7.3 & 6.4 & 6.0 & 6.2 & 6.8 \\
$95 \% \mathrm{Cl}$ & $4.9-10.4$ & $4.3-9.3$ & $4.0-8.8$ & $4.1-9.0$ & $4.6-9.7$ \\
Females & & & & & \\
$n$ & 29 & 25 & 30 & 26 & 26 \\
Incidence & 5.9 & 5.1 & 6.0 & 5.1 & 5.1 \\
$95 \% \mathrm{Cl}$ & $4.0-8.5$ & $3.3-7.5$ & $4.1-8.6$ & $3.3-7.5$ & $3.3-7.5$ \\
Total & & & & & \\
$n$ & 61 & 53 & 57 & 54 & 57 \\
Incidence & 6.6 & 5.7 & 6.0 & 5.6 & 5.9 \\
$95 \% \mathrm{Cl}$ & $5.1-8.6$ & $4.2-7.5$ & $4.6-7.6$ & $4.2-7.4$ & $4.5-7.7$ \\
\hline
\end{tabular}

male aged 52 years in 1992 . Thus, the primary and secondary sources identified at least $85 \%$ and probably more of newly-diagnosed patients in the study period. Except for the 26-year-old female, underascertainment was restricted to the over-50 year age group.

Table 2 shows age- and sex-specific rates for IDDM for the period 1988-1992. The incidence of IDDM was lowest in children aged 0-4 years, significantly increasing to a peak at age $10-14$ years. In the whole group, the peak incidence declines significantly in the 15-24-year age group, declining further after age 24 years, and remaining stable in older age groups. Sex- and age-specific rates reveal a significantly higher incidence in males than in females in the 5-9 and 25-44 year age groups $(p<0.05)$, the decline after age 24 years being less pronounced in males than in females, and non-significant until after age 44 years. However, females had a significantly higher rate in persons aged $45-54$ years $(p<0.05)$. No significant temporal differences (linear trend or deviation from mean distribution) were observed during the study period in the whole group, nor were they detected in different sex (Table 3) or age groups.

Although a greater proportion of cases was diagnosed in autumn and winter, an uneven seasonal distribution of IDDM cases could not be confirmed statistically for either the whole group, or for age groups 0-14 years, 15-34 years and 35+ years $(p>0.05)$. The seasonal pattern was not different for males or females $(p>0.05)$.

\section{Discussion}

The definition of IDDM in this study is a possible cause of underascertainment. Melton et al. [4] have shown that more than $90 \%$ of diabetic patients starting insulin treatment within 1 year of diagnosis are started on insulin during the first week after diagnosis. Still, a number of patients progressing to insulin therapy after some months have not been included in the numerators. On the other hand, our data might include "false positive" IDDM patients. Although it has been shown that more than $80 \%$ of withdrawals from insulin occurred during the first year [4], the decision to withdraw insulin could depend on the individual physician. Also, some patients were followed for less than a year after diagnosis.

The primary source identified a high proportion of patients, the ascertainment varying only slightly in the study period. However, the existing diabetes registry does not seem to be adequate for identifying incident cases in persons older than 50 years. Early fatality seems to influence the incidence rates in this age group, since $14 \%$ of incident cases in this age group was identified solely through death certificates, thus supporting data on the high mortality of newly-diagnosed IDDM in the elderly [18]. Of the patients who died before being registered, none had had diabetes diagnosed previously. Two patients died at home, without medical attendance. The coroner ascribed their death to diabetic ketoacidosis (DKA). The other patients were admitted to hospital in DKA and died within 2-48 h of admission. Only one patient was conscious on admission. In at least four of the eight deceased patients, death could be ascribed exclusively to DKA, while the others subsequently developed conditions which probably contributed to early death. It was not possible to determine how many patients had sought medical care prior to admission with DKA. Therefore it is difficult to say whether this serious condition on admission to hospital is a result of failure to recognize the symptoms of DKA in middle-aged and elderly persons, or a result of swift metabolic deterioration without pronounced symptoms.

The incidence rates in this study are lower than those reported for several other countries in a similar study period, particularly in persons younger than 30 years $[6,8,19,20]$. Childhood incidence of IDDM in Zagreb appears to be low and similar to that of other European populations of Slavic origin and populations of Southern Europe [2]. The peak incidence occurring in the 10-14 year age group in this Croatian population has also been reported for many other populations with very different rates [20-24]. The rates in the 15-30 age group are closest to those found in Turin and the Turin Province, and the Lombardy region in Italy $[21,22,25,26]$.

It has been proposed to categorize populations into low, intermediate and high IDDM risk groups, according to incidence in persons younger than 20 years [1]. If these criteria are accepted, the population of Zagreb is not at high risk of IDDM, the incidence being less than 15 per 100,000. There are only a few studies describing the incidence of IDDM in all age groups, and most research has been done in high-risk populations $[4,8,19,27]$. The stable inci- 
dence after a decline beyond age 24 years is a finding different from the decrease in incidence after age 50 years observed in Estonia [19]. It is also different from the findings of a second peak occurring in old age $[4,8,28]$.

A higher incidence in males was found in the 5-9year-old children, but not in teenagers and adults younger than 25 years, as found in some studies [ 6 , $20,21,23]$. However, in the 25-44 year age group the incidence of IDDM is significantly higher in males, thus supporting the hypothesis of the possible effect of lifestyle, rather than sex hormones, on IDDM incidence [6]. However, this difference in risk does not persist in older age groups. A higher incidence in females was found in the age group 45-54 years, and both sexes had a similar incidence after age 55 years. This finding is difficult to explain in terms of lifestyle factors.

No secular trend was detected in the study period. The small size of the study population is likely to have decreased the power of detecting temporal variation. We had hypothesized that the war-related events in Croatia affected the incidence of IDDM in the population of Zagreb. During the war in Croatia, starting in the summer of 1991, the area of Zagreb was not the site of direct combat. However, the city was bombed once, there were daily air-raid alarms and the sounds of combat were audible from the front line only 30 kilometres away. Many inhabitants, particularly younger males, were directly involved in warfare. The incidence of IDDM does not seem to have been affected by war-related events. Although it was expected that an effect could be demonstrated within 18 months of exposure to war-related stressors, it is too early to conclude that the effect of war was negligible, as clinical onset of IDDM can be slow [29].

The absence of seasonal differences in the proportion of cases diagnosed could be caused by the relatively small sample size, although no seasonality had previously been reported from other studies conducted only in younger age groups $[21,30,31]$. The risk of IDDM in this population of Slavic origin is low, and the rates were not affected by the war so far. Underascertainment due to early fatality in older ages is likely to alter the IDDM rates. It is possible that this is a local, population-specific finding, therefore studies in other populations are necessary. It is recommended that death certificates be included as means of case ascertainment when measuring IDDM incidence in persons over 50 years of age, unless it has been demonstrated that this source does not improve the completeness of data.

Acknowledgements. Part of this study was performed through collaboration with the EU Concerted Action Project EURODIAB ACE (Contract No. BMH1 CT92-0043).

\section{References}

1. LaPorte ER, Tajima N, Åkerblom HK et al. (1985) Geographic differences in the risk of insulin-dependent diabetes mellitus: the importance of registries. Diabetes Care 8 [Suppl 1]: 101-107

2. Green A, Gale EAM, Patterson CC, The EURODIAB Subarea A Study Group (1992) Incidence of childhood-onset insulin-dependent diabetes mellitus: The EURODIAB ACE Study. Lancet 339: 905-909

3. Laakso M, Pyörälä K (1985) Age of onset and type of diabetes. Diabetes Care 8: 114-117

4. Melton LJ, III, Palumbo PJ, Chu-Pin C (1983) Incidence of diabetes mellitus by clinical type. Diabetes Care 6: 75-86

5. Michaelis D, Jutzi E, Vogt L (1993) Epidemiology of insulin-treated diabetes mellitus in the East-German population: differences in long-term trends between incidence and prevalence rates. Diabete Metab 19: 110-115

6. Blohmé G, Nyström L, Arnqvist HJ et al. (1992) Male predominance of type 1 (insulin-dependent) diabetes mellitus in young adults: results from a 5-year prospective nationwide study of the 15-34-year age group in Sweden. Diabetologia 35: 56-62

7. Pagano G, Cavallo-Perin P, Cavalot F et al. (1987) Genetic, immunologic, and environmental heterogeneity of IDDM. Incidence and 12-mo follow-up of an Italian population. Diabetes 36: 859-863

8. Scott RS, Brown LJ (1991) Prevalence and incidence of insulin-treated diabetes mellitus in adults in Canterbury. New Zealand. Diabet Med 8: 443-447

9. Škrabalo Z, Metelko Ž, Aganović I, Granić M (1987) Croatian Model - to consider appropriate technology for diabetes care programs in the community. Diabetologia Croatica 16: 109-140

10. Roglić G, Metelko Ž, Radica A, Kadrnka-Lovrenčić M, Granić M, Škrabalo Z (1991) Incidence of insulin-dependent diabetes mellitus - the Zagreb incidence registry. Diabetes 40 [Suppl 1]: 319 (Abstract)

11. Solomon GF, Amkraut AA, Rubin RT (1985) Stress, hormones, neuroregulation and immunity. In: Burchfield SR (ed) Stress: psychological and physiological interactions. Hemisphere, Washington, pp 207-221

12. Popis stanovništva 1991. Stanovništvo prema spolu i starosti. Republika Hrvatska. (Population census. Population by sex and age. Republic of Croatia). Državni zavod za statistiku. Dokumentacija 882. Zagreb, 1994

13. Wittes JT, Colton T, Sidel VW (1974) Capture-recapture methods for assessing the completeness of case ascertainment when using multiple information sources. J Chron Dis 27: 25-36

14. LaPorte RE, McCarty D, Bruno G, Tajima N, Baba S (1993) Counting diabetes in the next millenium. Diabetes Care 16: 528-534

15. Lilienfeld AM, Lilienfeld DE (1980) Foundations of epidemiology. Oxford University Press, New York Oxford, p 353

16. Lilienfeld AM, Lilienfeld DE (1980) Foundations of epidemiology. Oxford University Press, New York Oxford, pp 336-338

17. Freedman LS (1978) The use of a Kolmogorov-Smirnov type statistic in testing hypotheses about seasonal variation. J Epidemiol Community Health 33: 525-538

18. Gale EAM, Dornan TL, Tattersall RB (1981) Severely uncontrolled diabetes in the over fifties. Diabetologia 21: 25 28

19. Kalits I, Podar T (1990) Incidence and prevalence of type 1 (insulin-dependent) diabetes in Estonia in 1988. Diabetologia 33: 346-349 
20. Goday A, Castell C, Tresserras R, Canela J, Taberner JL, Lloveras $G$ and the Catalan Epidemiology Diabetes Study Group (1992) Incidence of type 1 (insulin-dependent) diabetes mellitus in Catalonia, Spain. Diabetologia 35: 267271

21. Bruno G, Merletti F, Vuolo A, Pisu E, Giorio M, Pagano G (1993) Sex differences in incidence of IDDM in age group 15-29 yr. Higher risk in males in Province of Turin, Italy. Diabetes Care 16: 133-136

22. Bruno G, Merletti F, Pisu E, Pastore G, Marengo C, Pagano G (1990) Incidence of IDDM during 1984-1986 in population aged $<30$ yr residents of Turin, Italy. Diabetes Care 13: 1051-1056

23. Allen C, Palta M, D'Alessio DJ (1986) Incidence and differences in urban-rural seasonal variation of type 1 (insulin-dependent) diabetes in Wisconsin. Diabetologia 29: $629-633$

24. Soltesz G, Madacsy L, Bekefi D, Danko I, the Hungarian Childhood Diabetes Epidemiology Group (1989) Rising incidence of type 1 diabetes in Hungarian children (19871987). Diabetic Med 7: 111-114

25. Garancini P, Gallus G, Calori G, Formigaro F, Micossi P (1991) Incidence and prevalence rates of diabetes mellitus in Italy from routine data: a methodological assessment. Eur J Epidemiol 7: 55-63

26. Calori G, Gallus G, Garancini P, Repetto F, Micossi P (1990) Identification of the cohort of type 1 diabetes presenting in Lombardy in 1983-1984: a validated assessment. Diabet Med 7: 595-599

27. Christau B, Mølbak AG (1984) Further epidemiological evidence of a higher incidence level for the insulin-dependent diabetes mellitus in older age groups. Acta Endocrinol [Suppl] 95: 18

28. Krolewski AS, Warram JH, Rand LI, Kahn CR (1987) Epidemiologic approach to the etiology of type 1 diabetes mellitus and its complications. N Engl J Med 317: 13901398

29. Tarn AC, Smith CP, Spencer KM, Bottazzo GF, Gale EAM (1987) Type I (insulin-dependent) diabetes: a disease of slow clinical onset? B M J 294: 342-345

30. Lorenzi M, Cagliero E, Schmidt NJ (1985) Racial differences in incidence of juvenile-onset type 1 diabetes: epidemiologic studies in southern California. Diabetologia 28: $734-738$

31. Crossley JR, Upsdell M (1980) The incidence of juvenile diabetes mellitus in New Zealand. Diabetologia 18: 29-34 